\title{
Article \\ Effect of Supra-Transus Deformation Conditions on Recrystallization of Beta Ti Alloy
}

\author{
Chao Voon Samuel Lim ${ }^{1, *} \mathbb{}{ }^{\text {, Yang Liu }}{ }^{1}$, Chen Ding ${ }^{2}$ and Aijun Huang ${ }^{1}$ \\ 1 Materials Science and Engineering, Monash Centre for Additive Manufacturing, Monash University, Clayton, \\ VIC 3168, Australia; Yang.Liu2@monash.edu (Y.L.); Aijun.huang@monash.edu (A.H.) \\ 2 BAOWU Special Metallurgy Titanium Technology Co., Ltd., Baoshan District, Shanghai 200940, China; \\ Dingchen@baosteel.com \\ * Correspondence: samuel.lim@monash.edu
}

Citation: Lim, C.V.S.; Liu, Y.; Ding,

C.; Huang, A. Effect of Supra-Transus Deformation Conditions on Recrystallization of Beta Ti Alloy. Metals 2021, 11, 1278. https:// doi.org/10.3390/met11081278

Academic Editor: Andrey Belyakov

Received: 5 July 2021

Accepted: 9 August 2021

Published: 12 August 2021

Publisher's Note: MDPI stays neutral with regard to jurisdictional claims in published maps and institutional affiliations.

Copyright: (c) 2021 by the authors. Licensee MDPI, Basel, Switzerland. This article is an open access article distributed under the terms and conditions of the Creative Commons Attribution (CC BY) license (https:/ / creativecommons.org/licenses/by/ $4.0 /)$.

\begin{abstract}
There is increasing usage of high strength Beta Ti alloy in aerospace components. However, one of the major challenges is to obtain homogeneous refined microstructures via the thermomechanical processing. To overcome this issue, an understanding of the hot deformation conditions effect on the microstructure, prior to and after annealing, is needed. In this work, the effect of strain levels, which is more precise than percentage of reduction, and strain rate under supra-transus deformation temperature on beta annealing are studied using a double cone sample. The Electron Backscattered Diffraction (EBSD) is used to determine the deformed microstructure and texture evolution, as well as the static recrystallized grains evolution using the ex situ annealing approach. This work provides evidence that the mechanisms of dynamic recovery and recrystallization, along with texture evolution, are affected by the deformation conditions, which in turn affected the subsequent static recrystallization during annealing. It will also be shown that high levels of strain do not necessarily lead to an increase in the rate of recrystallization. Finally, the results obtained provided several examples of guidance in designing the TMP processes for obtaining not only a refine microstructure, but a more homogeneous beta microstructure during the beta processing of Beta Ti alloy.
\end{abstract}

Keywords: beta titanium alloy; thermomechanical processing; dynamic recovery; recrystallization; annealing

\section{Introduction}

Titanium (Ti) alloys are widely used in the aerospace, marine, chemical, and biomedical industries, as well some other special applications, due to their unique set of properties such as relatively low density, high strength, good corrosion performance, and bio-compatibility. Thermo-mechanical processing (TMP) and heat treatment are used together in Ti alloy billet production to not only bring the initial cast ingot down to size, but to also improve their mechanical properties by modifying the microstructure [1,2]. All Ti alloy billets will be hot processed initially in the supra-transus region (above beta transus) to break down the cast microstructure, and also to refine the beta grain size [3]. This will then be followed by sub-transus hot processing or a combination of sub-transus-supratransus-sub-transus processing. It is to be noted that how the TMP is conducted/designed has a considerable influence and effect on the microstructure and the mechanical properties of the Ti alloy.

Beta Ti alloys have attractive advantages compared to alpha+beta $\mathrm{Ti}$ alloys such as their increased heat treatability, wide and unique range of strength-to-weight ratios, deep hardenability potential, and inherent ductility [4-6]. Beta Ti alloys are considered high strength Ti alloys, and their application, particularly in the aerospace industry, has been growing for thick section components such as landing gear. However, the TMP processing of Beta $\mathrm{Ti}$ alloy has been challenging in trying to obtain refine and homogeneous beta 
grains in the billet. Supra-transus deformation/working can sometimes lead to mixed or inhomogeneous grain structure consisting of large and small grains. Such a result was attributed to selective recrystallization in regions of high strain along beta grain boundaries and the reduced driving force for recrystallization in the grain interiors, where dynamic recovery dominates [1]. Such selective recrystallization onset was observed as the formation of a necklace structure at borders of beta grains, which was stated to be related to dynamic recrystallization during the hot working process [7-9]. It has also been suspected that low beta forging temperature may be the cause leading to the development of non-completed beta recrystallization and texture [10].

The dominant mechanism for restoration during hot working is understood to be dynamic recovery (DRV) with very limited dynamic recrystallization (DRX) occurring for beta Ti alloys, as in Ti-17, deformed in the beta phase region [11], and also in the beta phase field of alpha and alpha+beta Ti alloys [2]. This was evident from apparent activation energy calculations which are generally found to be in the range of values obtained from the literature for self-diffusion in Beta Ti [4]. Importantly, this is seemingly only the case for high strain rate deformation. Zhu et al. [12] studied microstructure morphology with strain rates of $0.01-10 / \mathrm{s}$ of an alpha+beta Ti alloy TC21 (Ti-6Al-2Sn-2Zr-3Mo-1Cr-2Nb-Si) (beta transus $\sim 960^{\circ} \mathrm{C}$ ) during beta hot working. It was found that only DRV was observed at strain rates greater than $1 / \mathrm{s}$ as high strain rates are disadvantageous to nucleation of DRX [13]. This was corroborated by Balasubrahmanyam and Prasad observing DRX at strain rates ranging from $0.001-0.1 / \mathrm{s}$ while studying a beta Ti alloy (Ti-10V-4.5Fe-1.5Al) (beta transus $\sim 750^{\circ} \mathrm{C}$ ) [14]. It was also observed in their work, that the extent of DRX grows firstly and then decreases with decreasing strain rate. This was as excessive low strain rate gives enough time for DRV and suppresses DRX. However, for Chuan and Liang [15] studying Ti $5 \mathrm{Al}-5 \mathrm{~V}-5 \mathrm{Mo}-3 \mathrm{Cr}-1 \mathrm{Zr}$ (beta transus $\sim 845^{\circ} \mathrm{C}$ ), complete replacement of the elongated beta grains by newly equiaxed grains were observed for samples deformed to $60 \%$ reduction with a strain rate of $0.001 / \mathrm{s}$. With increasing strain rate, the number of recrystallized grains decreased in their study. From Wang et al. [16] who studied microstructure evolution for the alpha+beta Ti alloy Ti-6.5Al-3.5Mo-1.5Zr-0.3Si (beta transus $~ 1008{ }^{\circ} \mathrm{C}$ ) during beta working, it was found that DRV was observed at $1035-1080{ }^{\circ} \mathrm{C}$ at strain rates lower than $0.01 / \mathrm{s}$. Besides the strain rate effect, the deformation temperature also affects the microstructure evolution, where it has been found that DRX hardly occurs at lower temperatures in the beta phase field. The extent of DRX grows with an increase in temperature $[17,18]$. In addition, DRX of grains was found to be unobservable until a certain strain is reached, and the fraction of DRX grains grows sharply with strain [19].

Deformation in the single-phase beta field leads to DRV occurring particularly for the TMP converting ingot of Ti alloy to mill products. Hence, recrystallization of the beta-grain structure tends to occur only after deformation during annealing, or as the billet is reheated in the beta phase field for subsequent hot working. Pilchak et al. [20] has shown that the beta phase undergoes a process analogous to metadynamic recrystallization [21], characterized by the growth of a small population of pre-existing grains with high-angle boundaries into a matrix of beta subgrains. This was observed in beta annealing of Ti-6Al-4V after alpha+beta hot working. Fan et al. [3] showed that different pre-processing routes and their microstructures affected the recrystallization behaviour in the beta annealing of a near-beta Ti alloy (Ti-5Al-5Mo-5V-3Cr-1-Zr) (beta transus $\sim 835^{\circ} \mathrm{C}$ ). More importantly a non-fully recrystallized microstructure was observed for samples that were beta deformed and annealed at $865{ }^{\circ} \mathrm{C}$ even after $1 \mathrm{~h}$. Such phenomenon was similarly observed by Yan et al. [22] on a Ti-5Al-5Mo-5V-1Cr-1Fe (beta transus $\sim 870{ }^{\circ} \mathrm{C}$ ) forged bar that was annealed at $885^{\circ} \mathrm{C}$ for $0.5 \mathrm{~h}$. Such an inhomogeneous microstructure, having a non-fully recrystallized microstructure, can impact the mechanical properties. Thus, it is important and necessary to understand the factors causing such phenomenon to minimize and prevent their occurrence.

The ingot cast microstructure break-down process begins with the supra-transus deformation and annealing processes. The effect of any inhomogeneous microstructure 
developed after this stage of processing will remain in the subsequent alpha+beta TMP stage, and is difficult, or impossible, to remove. Therefore, it is critical for the understanding of supra-transus deformation conditions on the beta annealed microstructure. More importantly, this work seeks to identify the mechanisms and factors affecting the un-recrystallization of beta grains to provide explanation for their presence in forged beta Ti alloy which has been left unexplained in most studies [3,22]. This study focused on the deformation conditions of strain rate and strain, conducted at a beta deformation temperature, on the subsequent beta annealing behavior of a near-beta Ti alloy. This study also used the unique double cone samples for the systematic study of microstructure evolution with respect to different localized strain region at respective strain rates. This is unlike most studies, which use standard cylindrical samples, and the microstructure evolution is correlated to a global reduction percentage and not to localized specific strain values or range found in this work. EBSD analysis was used not only to characterize the deformed microstructure at the respective conditions, but also to identify recrystallized grains from the deformed grains using an ex situ annealing approach.

\section{Method}

The material used in the present work was sectioned from the center of a Ti-5Al-5V$5 \mathrm{Mo}-1 \mathrm{Cr}-1 \mathrm{Fe}$ forged billet. The beta transus temperature for this material was determined, via a series of heat treatment tests, to be around $870{ }^{\circ} \mathrm{C}$. The double cone sample shape and dimensions are similar to those established by Jackson et al. [23] with a major diameter of $19.8 \mathrm{~mm}$ and a major height of $15.8 \mathrm{~mm}$.

\section{(a) Isothermal compression}

Isothermal compression of the double-cone samples was performed using a mechanical $150 \mathrm{KN}$ Instron testing machine (INSTRON, Norwood, MA, USA). Specimen heating was provided by a resistance heating furnace with a maximum temperature of $1200{ }^{\circ} \mathrm{C}$. A control thermocouple was located $5 \mathrm{~mm}$ below the platen surface of the bottom ram. The furnace and the rams were heated up to the desired temperature before the sample was loaded, and then heated to the test temperature. The samples were held at the desired temperature for $5 \mathrm{~min}$ before deformation. The initial microstructure before deformation is shown in Figure 1. The beta grain size was about $230 \mu \mathrm{m}$ as measured from using the linear intercept method.

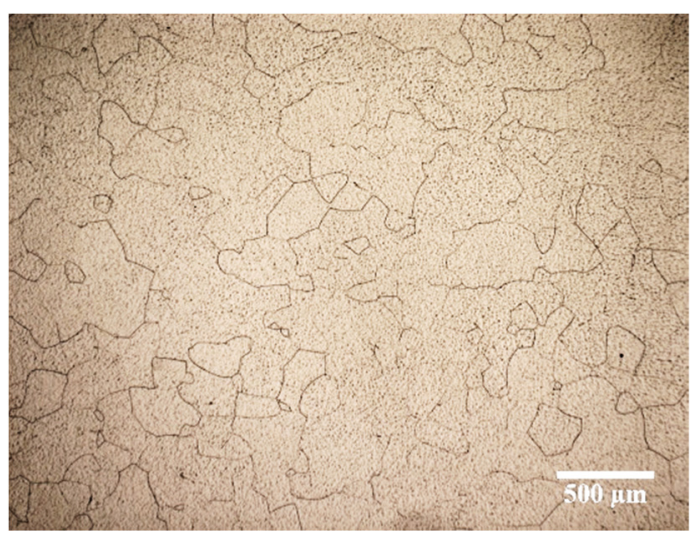

Figure 1. Microstructure of Ti55511 before deformation of a double-cone sample at $950{ }^{\circ} \mathrm{C}$.

The samples were compressed at a deformation temperature of $950{ }^{\circ} \mathrm{C}$ using constant cross-head speeds of $0.125 \mathrm{~mm} / \mathrm{s}, 1.25 \mathrm{~mm} / \mathrm{s}$, and $12.5 \mathrm{~mm} / \mathrm{s}$, which provide nominal initial strain rates of $0.01 / \mathrm{s}, 0.1 / \mathrm{s}$, and $1 / \mathrm{s}$, respectively. A constant speed method was chosen instead of constant strain rate, to mimic the speed condition in most industrial forging condition where the strain rate is not constant. The double-cone samples were compressed to a final height of about $5.0 \mathrm{~mm}$. No lubricants were used for the test. The 
as-deformed samples were water quenched immediately after the compression test was completed. The samples, deformed with respective nominal strain rates, were cut into quarters and subjected to post-deformation beta annealing at $950{ }^{\circ} \mathrm{C}$ using a tube furnace for various times of 2, 5, 7, 12, and $15 \mathrm{~min}$; followed by water quenching. The tube furnace was flashed with argon gas during the heat treatment, and the cut samples were wrapped in Tantalum foil to minimize oxidation.

\section{(b) Metallography and analysis}

The heat-treated samples were mechanically ground using SiC papers of grit sizes of 320 to 2500 , and finally polished using $0.05 \mu \mathrm{m}$ colloidal silica suspension mixed with hydrogen peroxide. The polished samples were ultrasonically cleaned and washed with ethanol solution. The polished samples were analyzed using a FEI Quanta FE-SEM (ThermoFisher Inc., Hillsboro, OR, USA) with TSL-EBSD system (AMETEK Inc., Berwyn, PA, USA). The EBSD scans were conducted using a step size of $2 \mu \mathrm{m}$, and each scan covered an area of $500 \mu \mathrm{m}$ by $500 \mu \mathrm{m}$. The measured points were cleaned by using the Neighbor CI correlation. Recrystallized grains were differentiated from the unrecrystallized using a Grain Orientation Spread (GOS) criteria of GOS less than or equal to 2 [24].

\section{(c) Finite element modelling}

The microstructure evolution and recrystallization kinetics verses local von Mises effective strain were deduced using position measurements in a SEM and finite-elementmethod (FEM) simulation of the double-cone test to obtain strain profiles as shown in Figure 2a. This was analogous to that performed by Jackson et al. [23]. The compression of the double cone sample was simulated using a rigid-plastic finite element program DEFORM-3D ${ }^{\mathrm{TM}}$. The input data consisted of the specific double-cone geometry and the flow stress data of the material. The flow stresses of the material were input by the tabular format based on flow curves obtained from compression tests conducted on axisymmetric cylindrical samples with similar initial microstructure to that of the double cone samples. The correct friction factor for the respective tests was found by matching the load stroke curves of different simulations having different friction factor (i.e., $m$ values) with the experimental load stroke curve (see Figure $2 b$ ). Once the friction factor for each test was identified, the dimension of the compressed sample obtained from the simulation was compared with the experimentally obtained data (Table 1) to further validate the simulation. Only when they were found to match well was the strain distribution obtained from simulation used to relate the microstructure and texture evolution to strain. The samples deformed at the same nominal strain rate are assumed to share the same simulation result, due to the similar deformation condition.

Table 1. Double cone deformed sample size measurements validating simulation geometric results.

\begin{tabular}{ccccc}
\hline Sample & Measured & Simulation & Measured & Simulation \\
\hline Cross-head Speed & \multicolumn{2}{c}{ Diameter $(\mathrm{mm})$} & \multicolumn{2}{c}{ Thickness $(\mathrm{mm})$} \\
\hline $0.125 \mathrm{~mm} / \mathrm{s}$ & 27.8 & 27.86 & 4.8 & 4.80 \\
\hline $1.25 \mathrm{~mm} / \mathrm{s}$ & 27.8 & 27.85 & 4.9 & 4.80 \\
\hline $12.5 \mathrm{~mm} / \mathrm{s}$ & 27.7 & 27.3 & 5.00 & 5.00 \\
\hline
\end{tabular}




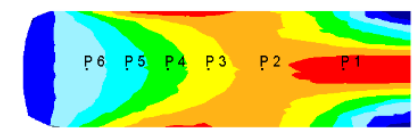

(a)

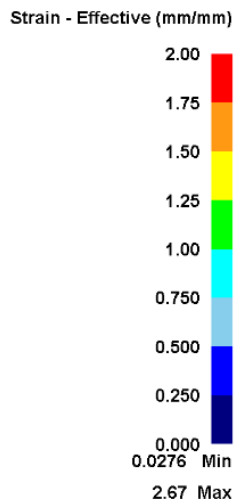

2.67 Max

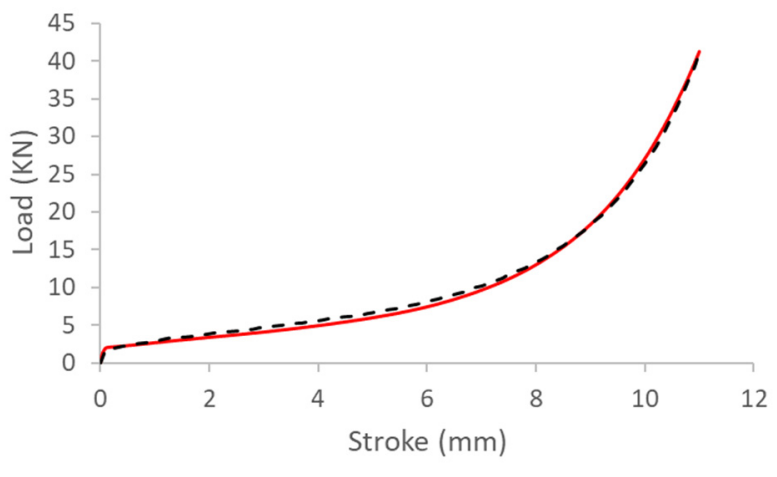

(b)

Figure 2. (a) Simulated effective strain distribution and ranges of a sectioned double-cone sample compressed at $950{ }^{\circ} \mathrm{C}$ with speed of $0.125 \mathrm{~mm} / \mathrm{s}$ representing nominal strain rate of $0.01 / \mathrm{s}$. P1 to P6 were locations at which microstructure analysis were conducted based on the respective strain ranges; (b) Experimental (solid) and simulation (dotted, $\mathrm{m}=0.8)$ obtained load-stroke curves for compression at $950{ }^{\circ} \mathrm{C}$ for nominal strain rates of $0.01 / \mathrm{s}$.

\section{Results and Discussion}

\subsection{Effect of Deformation Conditions on Deform Microstructure}

There is a morphological correlation with the strain range wherein the initial generally equiaxed beta grains became more elongated with strain. These were observed from the EBSD data obtained as shown in Figure 3, irrespective of nominal strain rates. From the low strain region of $0.5-0.75$ (in Figure $3 \mathrm{a}-\mathrm{c}$ ), the grains were not very relatively deformed, and beta grains have generally different crystallographic orientations. However, when the grains were deformed to higher strain ranges/levels greater than 1.25 , the beta grains have developed mainly similar orientations of $\{001\}$ as shown in the inverse pole-figure (IPF) microstructure map for sample deformed with nominal strain rate of 0.1 and $0.01 / \mathrm{s}$ (Figure $3 b, c)$. Interestingly, for the higher nominal strain rate of $1 / \mathrm{s}$, the deformed grains have grains with $\{111\}$ orientation as well as grains with $\{001\}$ orientations. This can be more clearly observed from Figure 4 wherein these $\{111\}$ and $\{100\}$ orientations developed with an increase in strain levels for the respective strain rates. At the low strain level of $0.5-0.75$, orientations can be considered generally random, or the crystallography texture is low, as seen from the low maximum intensity values. This is due to the fact that the microstructures were made up of fully recrystallized grains initially, prior to deformation, as was shown in Figure 1. As the strain increased, between 0.75 and 1.25, the $\{100\}$ and $\{111\}$ oriented grains began to develop. However, one can observe that the $\{100\}$ grains began to dominate samples under strain rates of 0.1 and $0.01 / \mathrm{s}$. This dominance became even greater beyond the strain levels of 1.25 , with the sample deformed at $0.01 / \mathrm{s}$ having only $\{100\}$ oriented grains, as can be seen from Figure 3c. On the other hand, one can observe the intensity of $\{111\}$ orientation is higher with an increase in strain rate at generally each of the similar strain levels imposed. This indicates that $\{111\}$ oriented grain development was very much strain rate related. Such observations are similar to that observed by Li et al. [24] using cylindrical samples of Ti55511 and compressed to various reductions between 20 and $80 \%$. With increasing deformation, i.e., strain levels, the low strain rates used favoured the development of $\{100\}$ texture. 
Grain Orientation
Spread
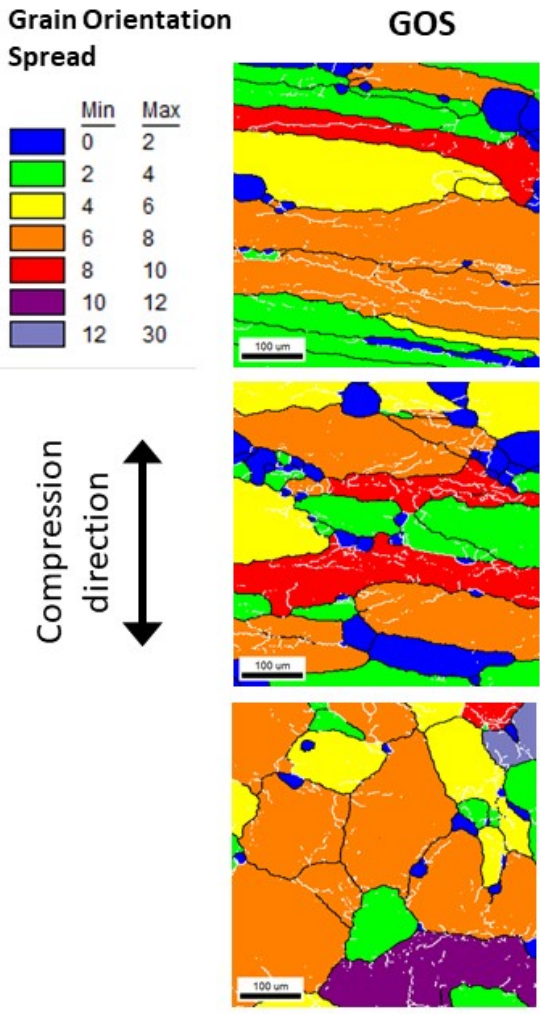

1.0-

1.25

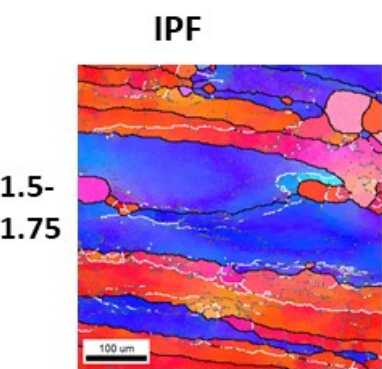

Inverse Pole

Figure

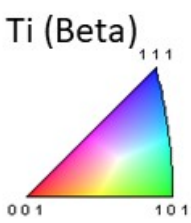

$0.5-$

0.75
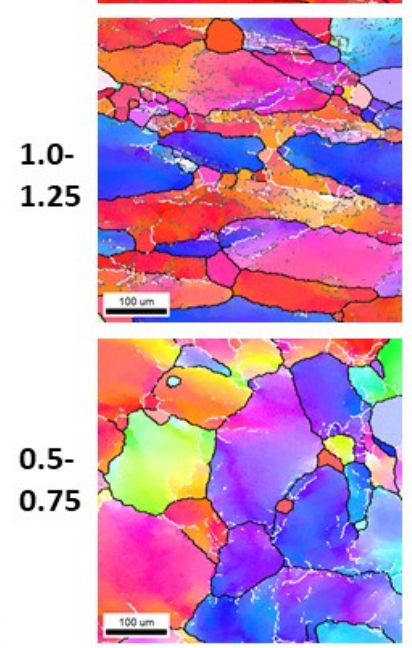

(a)
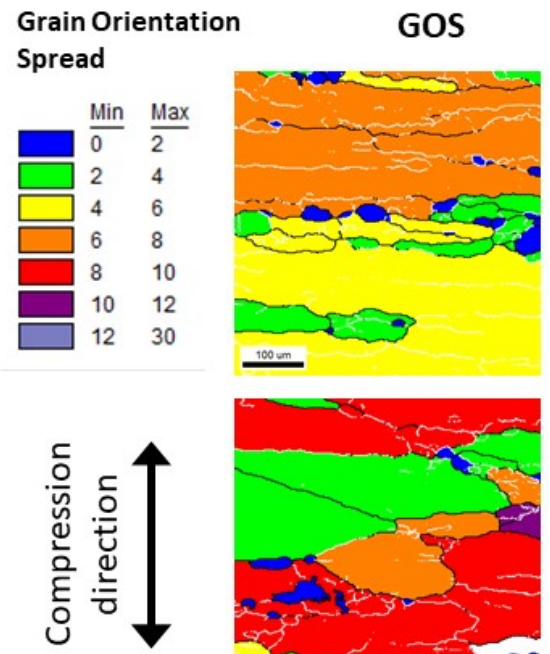

1.5-

1.75

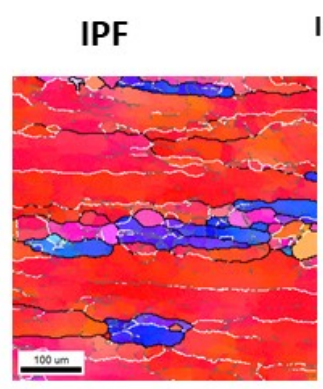

Inverse Pole

Figure

Ti (Beta)

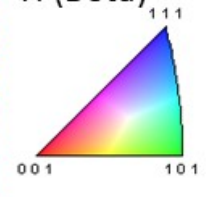

1.0-

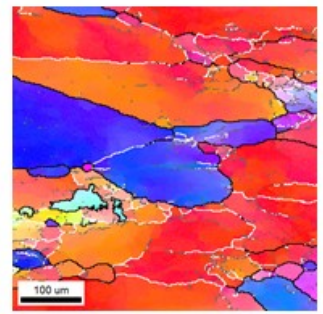

0.5-

0.75

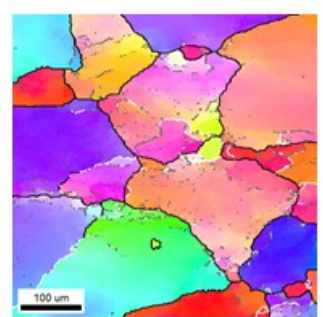

(b)

Figure 3. Cont. 

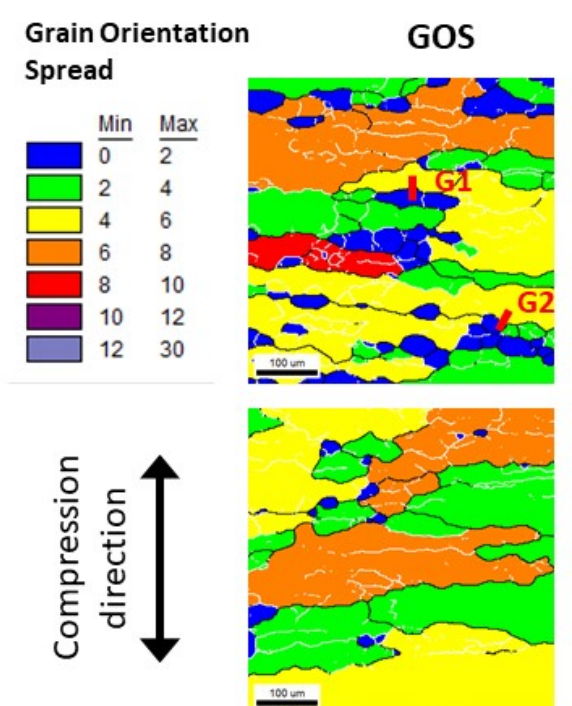

1.5

1.75

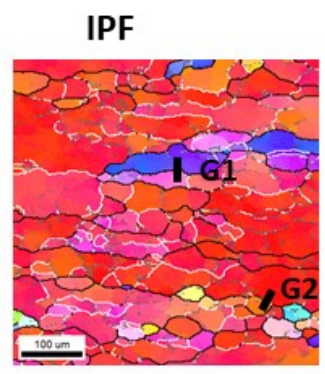

Inverse Pole

Figure

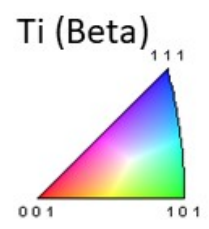

1.0-
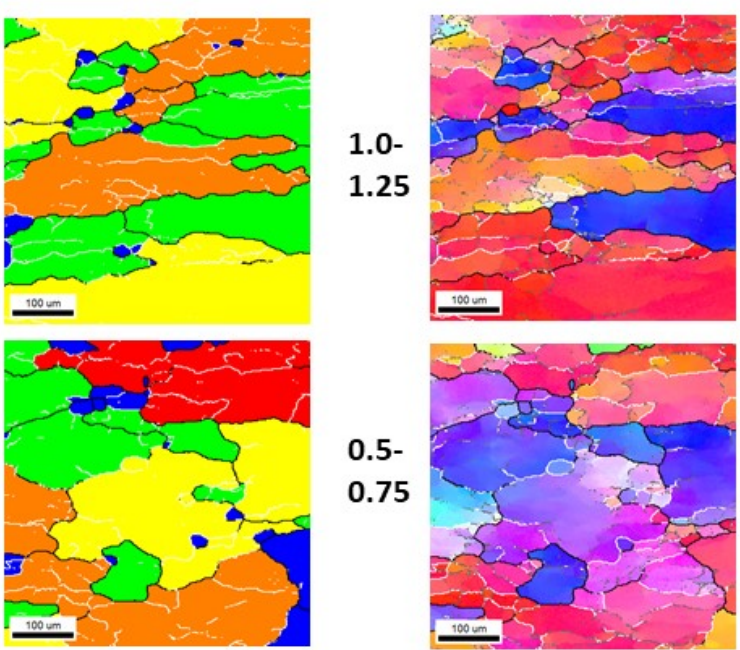

(c)

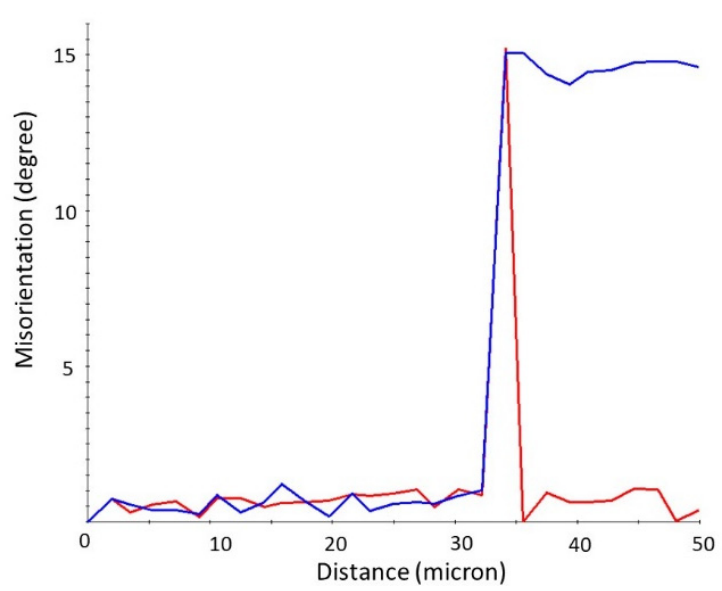

(e)

Figure 3. EBSD GOS and IPF maps of deformed microstructure of Ti55511 samples obtained for three different strain level regions that were deformed at $950{ }^{\circ} \mathrm{C}$ at nominal strain rates of (a) $1 / \mathrm{s},(\mathbf{b}) 0.1 / \mathrm{s}$, and (c) $0.01 / \mathrm{s}$. And misorientation measurement between grains of (d) G1 (having $\{001\}$ recrystallized red grain vs $\{111\}$ deformed blue grain) showing a higher misorientation than that of (e) G2 (having recrystallized red grain vs deformed red grain) at strain regions of 1.5-1.75 shown in (c). 


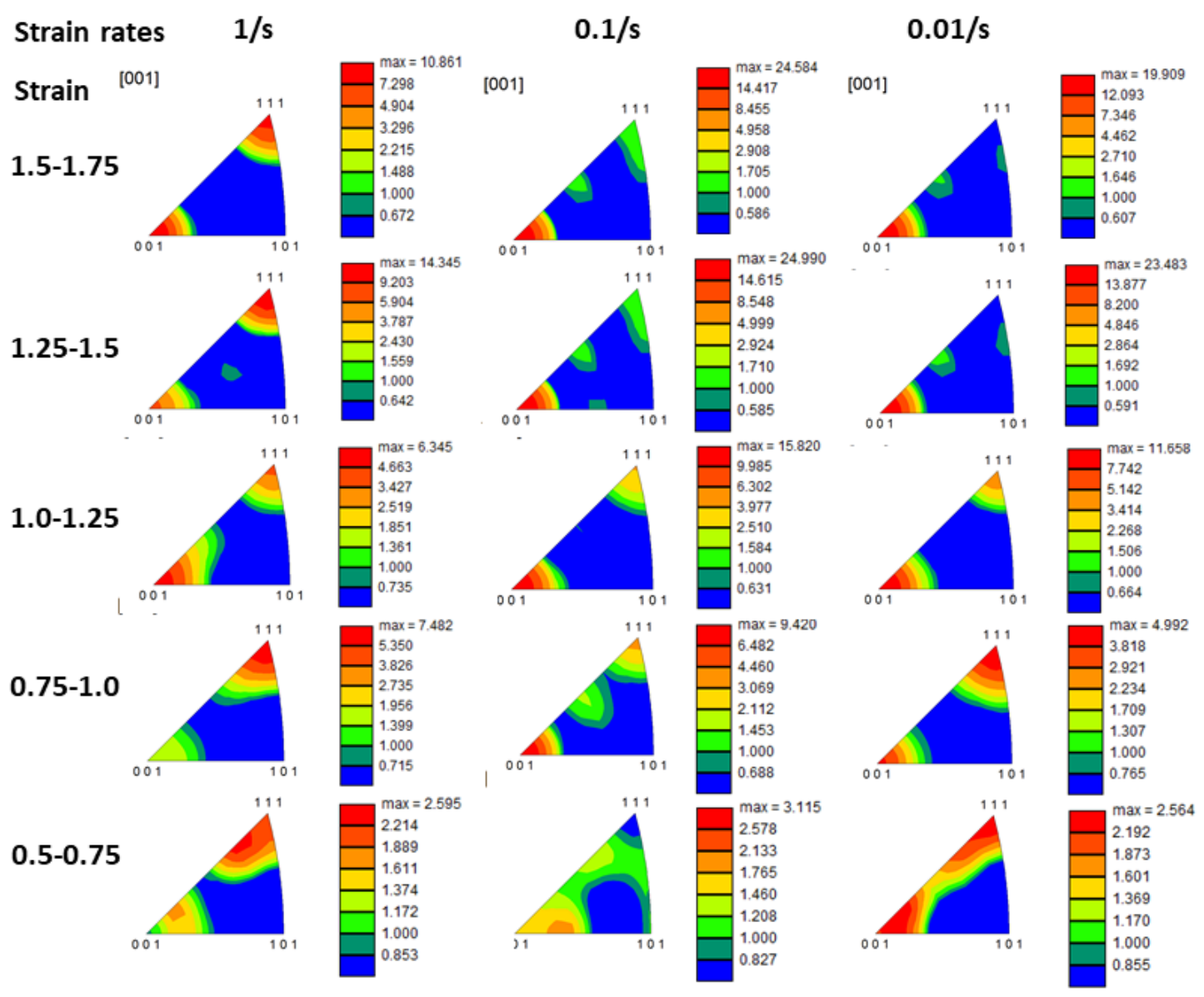

Figure 4. Inverse pole figures evolution with respect to the different strain regions and strain rate of the deformed Ti55511 at $950{ }^{\circ} \mathrm{C}$.

To understand the above phenomenon, one needs to understand the dynamic recrystallization and recovery mechanisms that were occurring. Some levels of dynamic recrystallization were identified by observing the GOS maps (see Figure 3). Grains in blue represent recrystallized grains as the GOS values for such grains were $0-2$. More specifically, there were some discontinuous dynamically recrystallized grains observed mainly at the grain boundaries between deformed grains for all the samples. This is due to the high angle boundaries serving as preferential sites for nucleation during recrystallization $[9,15,21]$. Most of the low angle boundaries were observed near the grain boundaries which indicate the dynamic recovery was controlling the deformation [25]. This was due to typical BCC metals having high stacking fault energy $[9,21]$ where dislocation climbing and cross-slipping promotes the dynamic recovery process. Although discontinuous dynamic recrystallization had occurred, it was not extensive where recrystallized grains had grown extensively and consumed many of the deformed grains. The amount of dynamic recrystallization grains is even lower for the higher strain rate sample, which was to be expected as recrystallization is a time-related process. However, it is important to note that the deformation texture changed for the 0.1 and $0.01 / \mathrm{s}$ strain rate samples after strain of 1.25 (see Figure 4 ) and the area fraction of grains with $<111>$ orientation decreased as shown in Figure 3. This can be attributed to Dynamic-Strain Induced Boundary Migration (D-SIBM) occurring during the hot deformation as was also suggested by Li et al. [24]. The new dynamically recrystallized grains nucleating at the grain boundary developed due to SIBM. These new grains mainly had orientations closer to $<001>$ oriented deformed grains which was also observed by Li et al. This is due to the growth of such near $<001>$ oriented nucleated grains being more favorable as compared to a near $\langle 111\rangle$ nucleated 
grain. In addition, the rate of boundary migration needs to be considered. The velocity, $\mathrm{v}$, of migration of the boundary is given as:

$$
\mathrm{V}=\mathrm{M} \Delta \mathrm{f}
$$

where $\mathrm{M}$ is the mobility and $\Delta \mathrm{f}$ is the driving force. From the stored energy aspect (i.e., $\Delta \mathrm{f}$ ), the $<111>$ oriented grains have a higher stored energy during compression [24] based on calculation which considered that the $<111>$ had a larger Talyor factor than $<100>$ grains when $\{101\}$ and $\{112\}$ slip systems were taken into account for BCC metals [26]. Therefore, the near $\langle 001\rangle$ nucleated grains will tend to grow into the $\langle 111\rangle$, driven by the relatively higher stored energy found in the $<111>$ grains. From the mobility aspect (i.e., M), the grain boundary of the near $<001>$ oriented grain naturally has a higher misorientation towards $<111>$ oriented grain compared to other $<001>$ oriented grains. This was evident when misorientation measurement was taken across the boundary of a $<001>$ recrystallized grain and a $<111>$ grain (G1 in Figure 3c,d) and that of a $<001>$ recrystallized grain and a $<001>$ deformed grain (G2 in Figure $3 c, e$ ), which was $35^{\circ}$ and $15^{\circ}$, respectively as shown in Figure $3 \mathrm{~d}$,e. Therefore, it can be envisioned the near $<001>$ recrystallized grains growing into the $<111>$ deformed grains and consuming them. Nevertheless, this growth will be impeded or slowed down when such grains meet other $<001>$ oriented grains. Besides their growth being impeded, such recrystallized grains would then also become deformed if the deformation process is continuing. The $<001>$ oriented deformed grains, on the other hand, will generally experience dynamic recovery and, with an increase in strain, further develop higher angle grain boundaries within the deformed grains while maintaining the deformed $<001>$ oriented texture. Thus, the deformation at slower nominal strain rates such as those of 0.1 and $0.01 /$ s provided the necessary time for the near $<001>$ recrystallized grains to grow and consume the majority of the $\langle 111\rangle$ deformed oriented grains when the critical strain level was attained (i.e., $\varepsilon_{\mathrm{c}}=1.25$ ). Nevertheless, there were minimum dynamic recrystallized grains in all the strain rates and strain level conditions and the $\{001\}$ deformed fibre texture remain. To obtain a fully recrystallized microstructure with a change in texture, static recrystallization from further heat treatment/annealing was required.

\subsection{Effect of Deformation Condition on Static Recrystallization}

Isothermal annealing at various times were conducted at $950{ }^{\circ} \mathrm{C}$ on the deformed double cone samples. The percentage of recrystallized grains was based on GOS calculation to determine if a grain was considered recrystallized, i.e., GOS values of $0-2$. The volume percentage of recrystallized grains at respective effective strain range for the samples with different nominal strain rates is shown in Figure 5. It can be observed that the volume fraction of recrystallization generally increases with annealing time. The rate of recrystallization was also observed to increase for sample with higher strain rate. This could be attributed to (i) the presence of different orientation grains, leading to preferential orientation growth mechanism, but it is more likely due to (ii) less dynamic recovery occurring for higher strain rate samples, allowing for the presence of a greater driving force of stored energy for static recrystallization to occur faster. Figure 6 is the GOS and IPF map that shows the microstructure evolution with the increase in annealing time. It can be observed that new grains generally nucleate and grow at the grain boundaries, as was observed for the deformed microstructure indicating discontinuous static recrystallization occurring. The new static recrystallized grains similarly have a $\{001\}$ orientation. On the other hand, for the nominal strain rate 0.01 / s condition, the rate of recrystallization was observably slower in comparison. This was attributable to the as-deformed microstructure having only grains with similar orientation (i.e., majority having $\{001\} / /$ TD orientation) and dynamic recovery occurring comparatively more due to the lower strain rate. Thus, even though new static discontinuous recrystallized grain did occur, they will grow and meet other grains of similar orientation, impeding their growth. In addition, there was less driving force for growth, as more dynamic recovery had occurred. 
It is generally taken that regions of higher strain will lead to greater and faster recrystallization due to associated increases in dislocation and driving force for recrystallization. However, this was not clearly observed for samples deformed at higher strain rates in this study. It was observed that the rate of recrystallization generally increased with an increase in strain levels for the nominal strain rate of $0.01 / \mathrm{s}$ sample. This followed the understanding that was based on the presence of a greater driving force for static recrystallization in region experiencing high strain than for the lower strain level regions. Interestingly, this was not the situation for the samples with nominal strain rates of 0.1 and $1 / \mathrm{s}$, particularly for regions between strain levels of $1.0-1.25$ and that of 1.5-1.75. The rate of recrystallization for the highest strain range of 1.5-1.75 tend to have a slower recrystallization rate than the lower strain range of 1.0-1.25. It is noted that the grains that were not recrystallized, or rather last to recrystallize, or consumed by recrystallized grains, were grains with $\{001\}$ orientations. As the strain levels increased from $0.5-0.75$ to those of $1.5-1.75$, it was observed that the $0.1 / \mathrm{s}$ samples had majority of grains having $\{001\}$ orientation and the $1 / \mathrm{s}$ sample had grains having a mixed of $\{001\}$ and $\{111\}$ orientations (Figure 3a,b). With an increase in strain level from 1.0-1.25 to that of 1.5-1.75, further dynamic recovery could occur as well, and more low angle boundaries were also being transformed into higher angle boundaries, with the increase in strain leading to less driving force for recrystallization grain growth to occur subsequently during the static annealing process. In other words, the $\{001\}$ oriented grain were considerably more "stable" in the high strain region of 1.5-1.75 compared to those at the lower strain region of 1.0-1.25. Thus, the rate of recrystallization was comparatively slower with an increase in strain beyond 1.5 for samples deformed with nominal strain rates of 0.1 and $1 / \mathrm{s}$. Such finding of a decreased of rate of recrystallization at higher strain level goes against what is commonly believed, i.e., that recrystallization rate increased with strain. However, what is usually not considered in that understanding is the role that texture could be playing as well [21], which is being highlighted and mentioned in this work. Nevertheless, more work should be completed regarding highly strained beat Ti alloys to elucidate if such a phenomenon is observed in other beta Ti alloy systems as well.

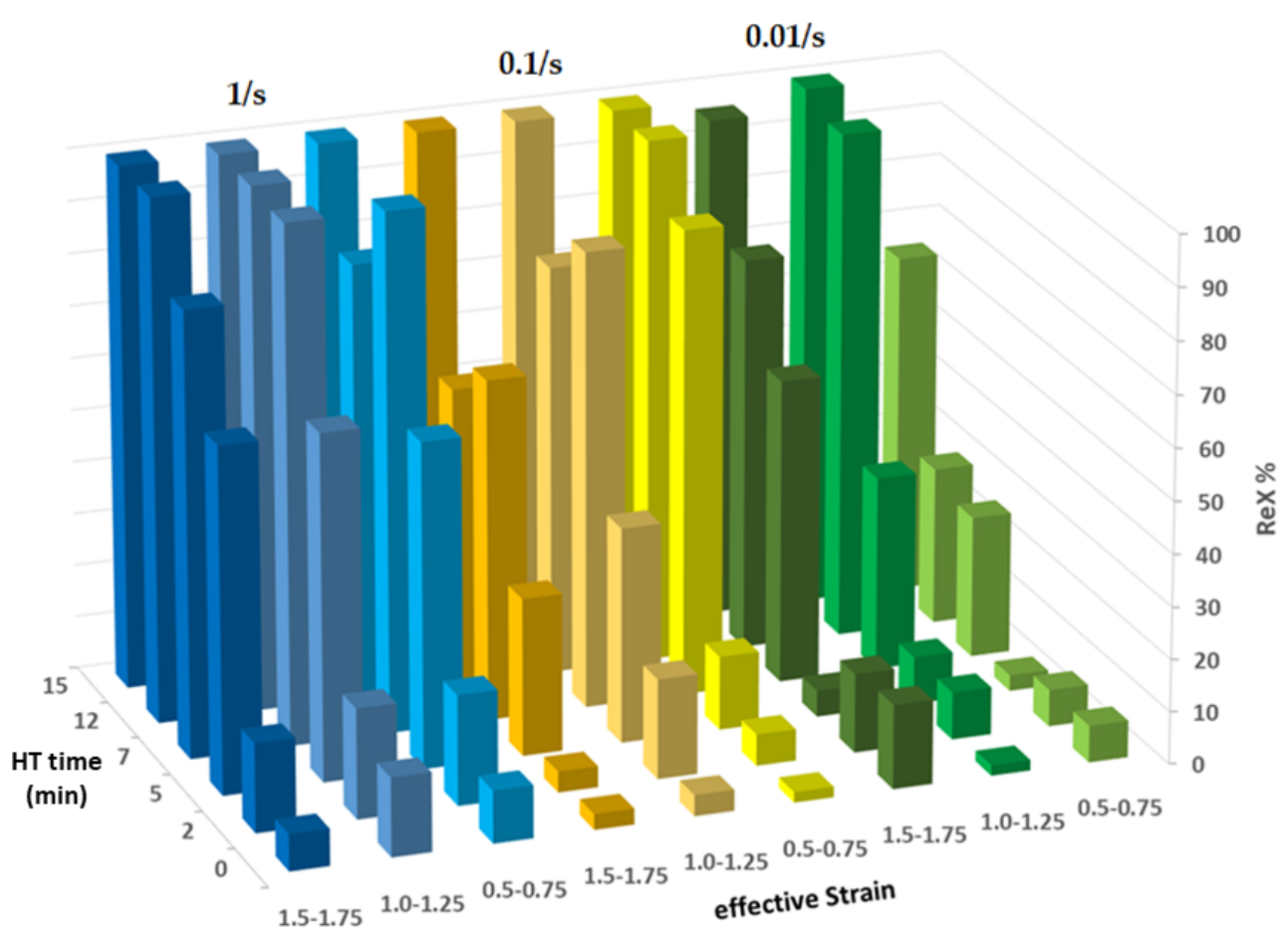

Figure 5. Chart showing amount of recrystallization evolution with respect to strain region, deformation strain rates, and annealing time at annealing temperature of $950{ }^{\circ} \mathrm{C}$. 
Strain range

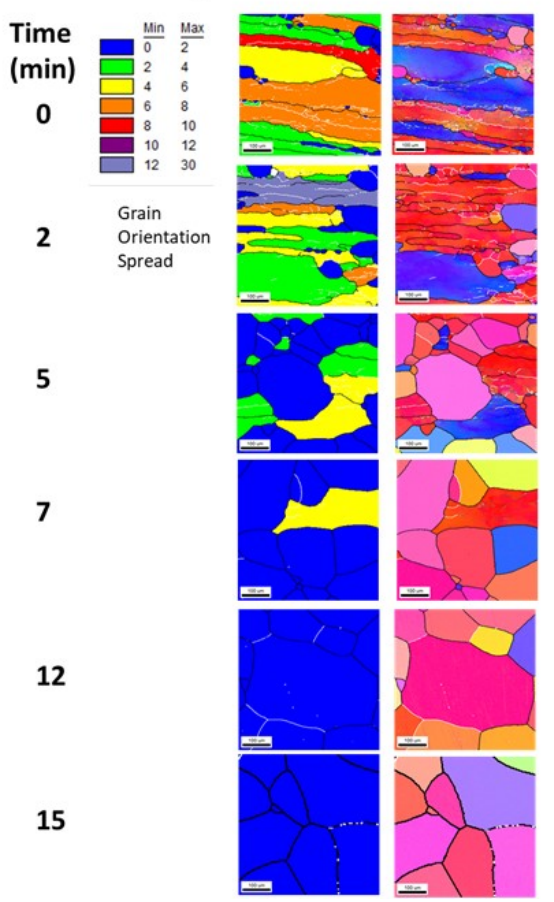

Strain range

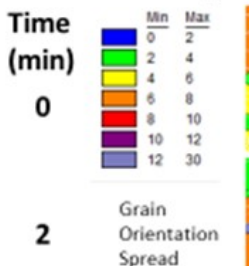

12

15
1.0-1.25
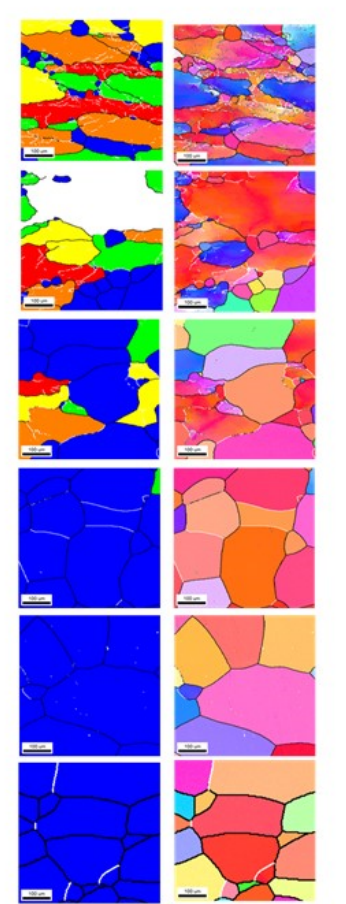

(a)

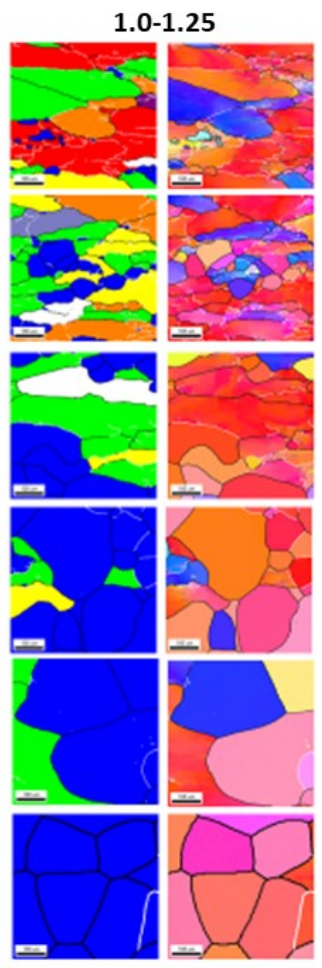

(b)
0.5-0.75
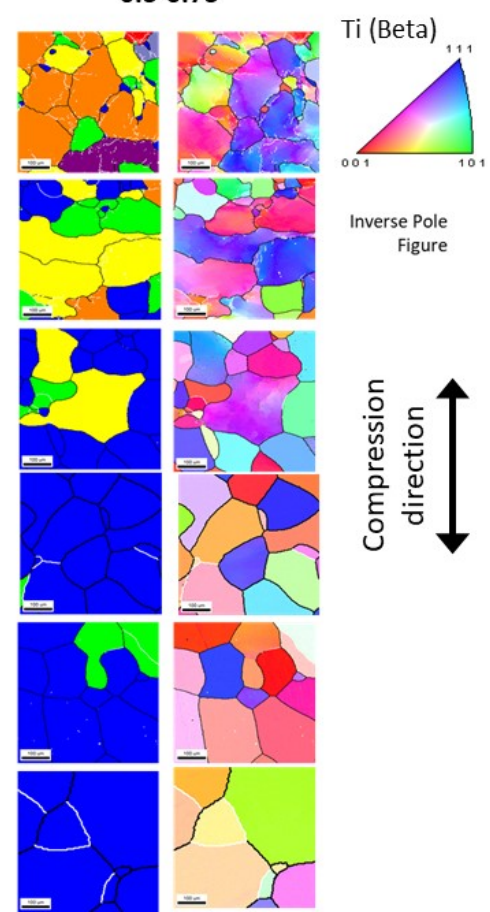

0.5-0.75
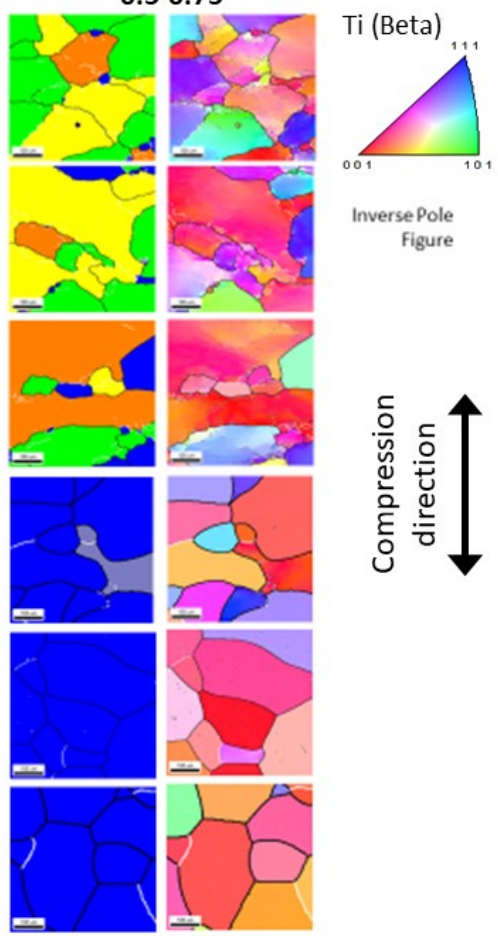

Inverse Pole

Figure

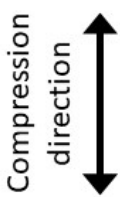

Figure 6. Cont. 

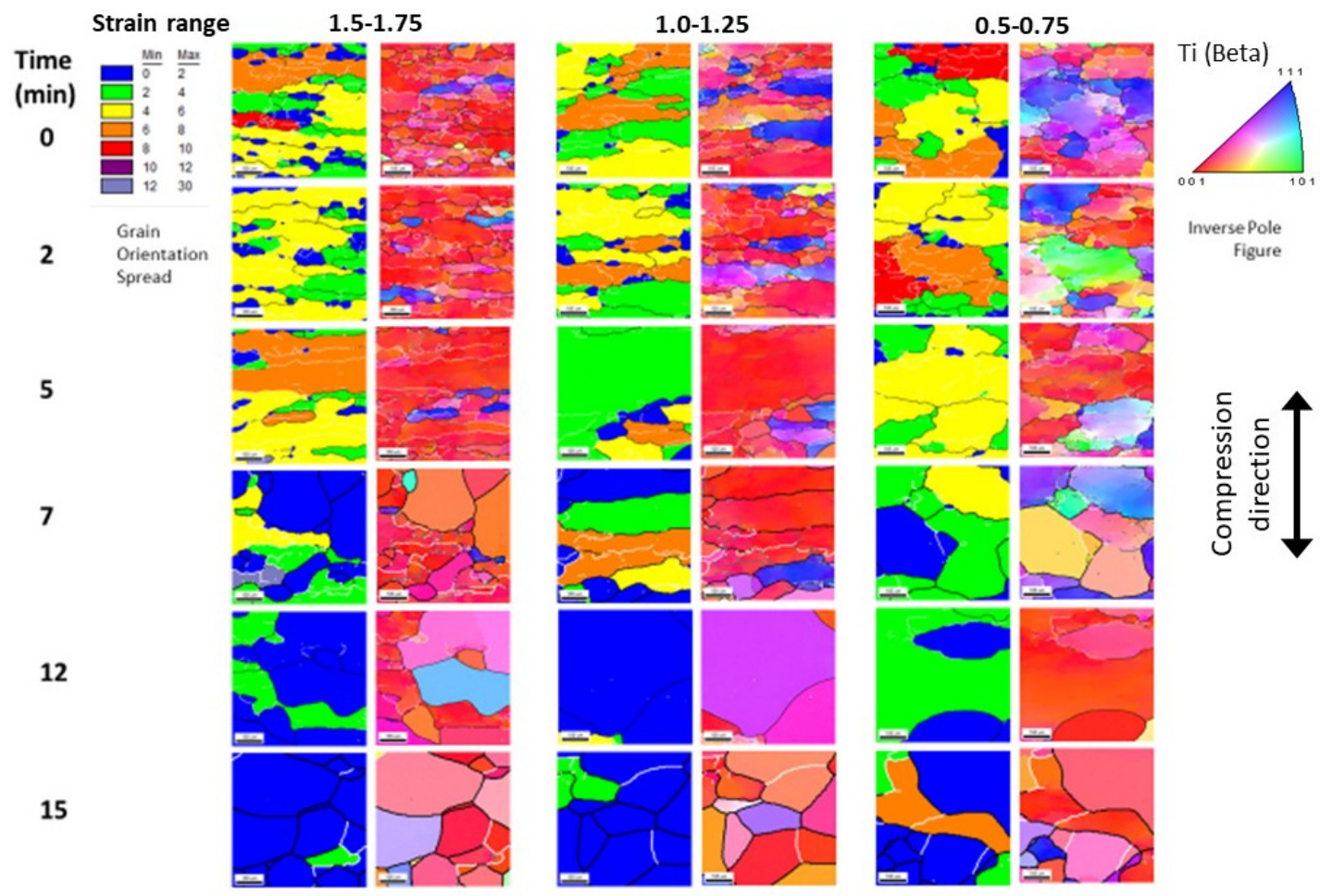

(c)

Figure 6. GOS and IPF maps showing the microstructure evolution of sample deformed with a nominal strain rate of (a) $1 / \mathrm{s}$, (b) $0.1 / \mathrm{s}$, and (c) $0.01 / \mathrm{s}$, at the respective strain range after annealing at $950{ }^{\circ} \mathrm{C}$ for various time.

\subsection{Effect of Varying Static Recrystallization Rate}

The above phenomenon of a reduction in recrystallization at higher strain region does highlight that an increase in strain levels through more deformation forging imposed during the beta forging of Ti alloy billet could lead to the development of inhomogeneous recrystallized microstructure. It is to be mentioned that the forging speed imposed during the billet forging of Ti alloy is around the nominal strain rate of $0.1 / \mathrm{s}$. A longer annealing time, i.e., up to and beyond $15 \mathrm{~min}$ at $950{ }^{\circ} \mathrm{C}$, did eventually lead to a fully recrystallized microstructure at all strain levels in this study. However, in trying to prevent grain growth of the beta grains, lower annealing temperatures such as $900{ }^{\circ} \mathrm{C}$ are usually used for static recrystallization annealing of Ti55511 alloy. The lower temperature used, which is $\beta_{\mathrm{T}}$ (i.e., beta transus) $+30{ }^{\circ} \mathrm{C}$, can exacerbate the slower recrystallization issue. This was indeed observed in experiments wherein cylindrical samples (i.e., $8 \mathrm{~mm}$ diameter $\times$ $12 \mathrm{~mm}$ in height) were compressed with a constant strain rate of $0.1 / \mathrm{s}$ at $1100{ }^{\circ} \mathrm{C}$ to $60 \%$ reduction, gas quenched, and then annealed at temperatures of 800,900 , and $1000{ }^{\circ} \mathrm{C}$ for $1 \mathrm{~h}$. The annealed microstructures are shown in Figure 7. It can be observed that there is no recrystallization of the beta grains at $800{ }^{\circ} \mathrm{C}$ annealing (Figure 7c), while the beta grains were fully recrystallized at $1000^{\circ} \mathrm{C}$ (Figure 7a). However, the sample annealed at $900{ }^{\circ} \mathrm{C}$ (Figure $7 \mathrm{~b}$ ) showed presence of deformed (unrecrystallized) grains in the midst of recrystallized grains, even after $1 \mathrm{~h}$ of annealing. Such a phenomenon has also been observed by others looking at forged billet of TC18, i.e., Ti55511, with annealing temperature of $900{ }^{\circ} \mathrm{C}$ for $0.5 \mathrm{~h}$ [22]. Presence of such unrecrystallized beta grain shows the issue of inhomogeneous microstructure development in the thermomechanical forging of Ti alloy billets. Moreover, it highlights the need to understand the effect of deformation conditions and the subsequent annealing temperature selection on the recrystallization microstructure. 


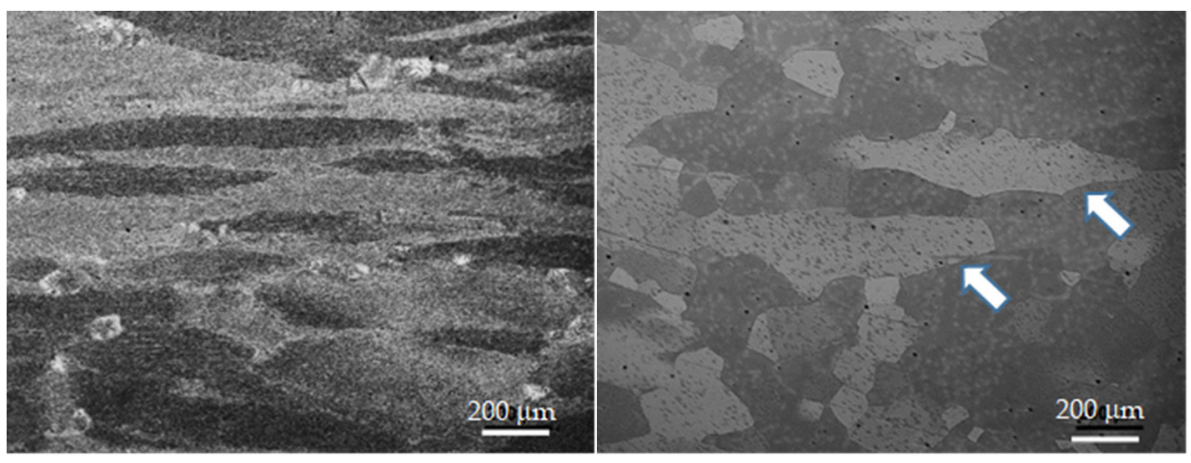

(a)

(b)

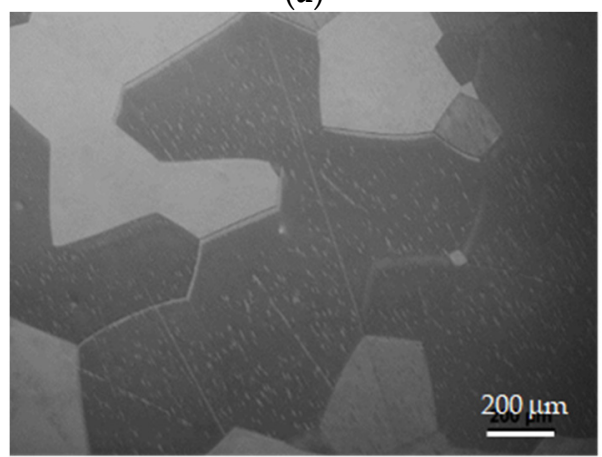

(c)

Figure 7. Optical micrographs showing the annealed microstructure at the centre region of Ti55511 cylindrical samples compressed to $60 \%$ reduction at $1100{ }^{\circ} \mathrm{C}$ with $0.1 / \mathrm{s}$ and annealed for $1 \mathrm{~h}$ at (a) $800{ }^{\circ} \mathrm{C}$, (b) $900{ }^{\circ} \mathrm{C}$, and (c) $1000^{\circ} \mathrm{C}$. The beta transus of Ti55511 is $870{ }^{\circ} \mathrm{C}$. Deformed (unrecrystallized) grains are pointed out by the white arrows in (b).

To obtain a homogeneous and fully recrystallized billet after supra-transus deformation, it is recommended to firstly seek to attain a more homogeneous strain distribution through the forging scheme of the forged billet. The strain level from our study indicates that recrystallization is not dependent on high strain levels. Next, a slightly higher static annealing temperature of possibly $\beta_{\mathrm{T}}+60^{\circ} \mathrm{C}$ should be considered, with adequate time of at least $1 \mathrm{~h}$. Finally, an intermediate sub-transus deformation step should be included to promote recrystallization, as was shown by Fan et al. [3]. Nevertheless, a homogeneous strain level distribution will be paramount if a homogeneous fully recrystallized beta grains microstructure is desired.

\section{Conclusions}

Through this study of using double cone samples of Ti55511, deformed at various nominal strain rates and subsequently annealing at $950{ }^{\circ} \mathrm{C}$ for various times, several conclusions can be made to understand the supra-transus deformation condition effect on static recrystallization in beta Ti alloy.

(i) The deformation strain rate affects the deformation texture at different strain levels. For the samples deformed at 0.1 and $0.01 / \mathrm{s}$, the mix of $\{001\}$ and $\{111\} / /$ TD oriented grains was dominated by $\{001\}$ oriented grains at strain level beyond 1.25;

(ii) The deformation mechanism was mainly governed by dynamic recovery, although a very low level of discontinuous dynamic recrystallization was also observed;

(iii) Dynamic strain-induced boundary migration was likely responsible for the consuming or disappearance of the $\{111\}$ oriented grains during deformation at higher strain levels;

(iv) The higher strain rate samples have faster recrystallization rates compared to the sample with strain rate of $0.01 / \mathrm{s}$; 
(v) In the higher strain regions for samples deformed at strain rates of 0.1 and $1 / \mathrm{s}$, the recrystallization was slower than the lower strain regions, which was attributed to the increase stability of the $\{001\}$ grains;

(vi) The reduced rate of recrystallization found in Ti55511 is exacerbated if the recrystallization temperature is lower, leading to presence of unrecrystallized grains and development of inhomogeneous microstructure.

Author Contributions: Conceptualization, C.V.S.L. and C.D.; methodology, C.V.S.L.; validation, C.V.S.L. and Y.L.; formal analysis, C.V.S.L.; investigation, C.V.S.L. and Y.L.; resources, A.H. and C.D.; data curation, C.V.S.L.; writing — original draft preparation, C.V.S.L.; writing — review and editing, C.V.S.L., A.H. and C.D.; visualization, C.V.S.L.; supervision, C.V.S.L. and C.D.; project administration, C.V.S.L.; funding acquisition, C.V.S.L. and C.D. All authors have read and agreed to the published version of the manuscript.

Funding: The authors are grateful and acknowledge the financial support from Baosteel Australia Joint Research Centre (BA16003) as well as ARC Research Hub for Computational Particle Technology (IH140100035).

Informed Consent Statement: Not applicable.

Data Availability Statement: The data presented in this study are available on request from corresponding author.

Acknowledgments: The authors also acknowledge the use of facilities within the Monash Center for Electron Microscopy (MCEM) particularly the electron microscope funded by Australian Research Council grant LE0882821.

Conflicts of Interest: The authors declare no conflict of interest. The permission of publication from Baosteel Australia Joint Research Centre has been granted. Other funder had no role in the design of the study; in the collection, analyses, or interpretation of data; in the writing of the manuscript, or in the decision to publish the results.

\section{References}

1. Sen, M.; Suman, S.; Kumar, M.; Banerjee, T.; Bhattacharjee, A.; Kar, S.K. Thermo-mechanical processing window for $\beta$ phase recrystallization inTi-5Al-5Mo-5V-3Cr alloy. Mater. Charact. 2018, 146, 55-70. [CrossRef]

2. Banerjee, D.; Pilchak, A.L.; Williams, J.C. Processing, Structure, Texture and Microtexture in Titanium Alloys. Mater. Sci. Forum 2012, 710, 66-84. [CrossRef]

3. Fan, X.G.; Zhang, Y.; Zheng, H.J.; Zhang, Z.Q.; Gao, P.F.; Zhan, M. Pre-processing related recrystallization behavior in $\beta$ annealing of a near- $\beta$ Ti-5Al-5Mo-5V-3Cr-1Zr titanium alloy. Mater. Charact. 2018, 137, 151-161. [CrossRef]

4. Weiss, I.; Semiatin, S.L. Thermomechanical processing of beta titanium alloys-An overview. Mater. Sci. Eng. A 1998, 243, 46-65. [CrossRef]

5. Cotton, J.D.; Briggs, R.D.; Boyer, R.R.; Tamirisakandala, S.; Russo, P.; Shchetnikov, N.; Fanning, J.C. State of the Art in Beta Titanium Alloys for Airframe Applications. JOM 2015, 67, 1281-1303. [CrossRef]

6. Boyer, R.R.; Briggs, R.D. The use of $\beta$ titanium alloys in the aerospace industry. J. Mater. Eng. Perform. 2005, 14, 681-685. [CrossRef]

7. Warchomicka, F.; Poletti, C.; Stockinger, M. Study of the hot deformation behaviour in Ti-5Al-5Mo-5V-3Cr-1Zr. Mater. Sci. Eng. A 2011, 528, 8277-8285. [CrossRef]

8. Chaussy, F.; Driver, J.H. Beta Titanium Alloys; Vassel, A., Eylon, D., Combres, Y., Eds.; Editions De la Revue de Metallurgie; French Society of Metallurgy and Materials: Paris, France, 1994; pp. 57-64.

9. Jiang, Y.; Lin, Y.C.; Wang, G.; Pang, G.; Chen, M.; Huang, Z. Microstructure evolution and a unified constitutive model for a Ti-55511 alloy deformed in $\beta$ region. J. Alloys Compd. 2021, 870, 159534. [CrossRef]

10. Shao, H.; Shan, D.; Wang, K.; Zhang, G.; Zhao, Y. Massive $\alpha$ precipitation selectivity and tensile fracture behavior of TC18 alloy. J. Alloys Compd. 2019, 797, 10-17. [CrossRef]

11. Yamanaka, K.; Matsumoto, H.; Chiba, A. A constitutive model and processing maps describing the high temperature behavior of Ti-17 alloy in the b-phase field. Adv. Eng. Mater. 2019, 21, 1800775. [CrossRef]

12. Zhu, Z.S.; Wang, X.N.; Gu, W.; Chen, M.H. A study on high temperature deformation behaviors of new type TC21 Titanium alloy. Mater. China 2009, 28, 51-55.

13. Ouyang, D.L.; Lu, S.Q.; Cui, X.; Wu, C.; Dong, X.J. Dynamic recrystallization of TA15 alloy during beta hot process at different strain rates. Rare Met. Mater. Eng. 2011, 40, 325-330. 
14. Balasubrahmanyam, V.V.; Prasad, Y.V.R.K. Deformation behaviour of beta titanium alloy Ti-10V-4.5Fe-1.5Al in hot upset forging. Mater. Sci. Eng. A 2002, 336, 150-158. [CrossRef]

15. Chuan, W.; Liang, H. Hot deformation and dynamic recrystallization of a near-beta titanium alloy in the $\beta$ singe phase region. Vacuum 2018, 156, 384-401. [CrossRef]

16. Wang, K.; Lu, S.; Fu, M.W.; Li, X.; Dong, X. Optimization of $\beta /$ near- $\beta$ forging process parameters of Ti-6.5Al-3.5Mo-1.5Zr-0.3Si by using processing maps. Mater. Charact. 2009, 60, 492-498. [CrossRef]

17. Zhu, Y.C.; Zeng, W.D.; Liu, J.L.; Zhao, Y.Q.; Zhou, Y.G.; Yu, H.Q. Effect of processing parameters on the hot deformation behavior of as-cast TC21 titanium alloy. Mater. Des. 2012, 33, 264-272. [CrossRef]

18. Jia, W.; Zeng, W.; Liu, J.; Zhou, Y.; Wang, Q. On the influence of processing parameters on microstructural evolution of a near alpha titanium alloy. Mater. Sci. Eng. A 2011, 530, 135-143. [CrossRef]

19. Ma, F.; Lu, W.; Qin, J.; Zhang, D. Microstructure evolution of near- $\alpha$ titanium alloys during thermomechanical processing. Mater. Sci. Eng. A 2006, 416, 59-65. [CrossRef]

20. Pilchak, A.L.; Sargent, G.A.; Semiatin, S.L. Early Stages of Microstructure and Texture Evolution during Beta Annealing of Ti-6Al-4V. Metall. Mater. Trans. A Phys. Metall. Mater. Sci. 2018, 49, 908-919. [CrossRef]

21. Humphreys, F.J.; Hatherly, M. Recrystallization and Related Annealing Phenomena, 2nd ed.; Elsevier: Pergamon, UK, 2002; pp. 182-183, 390.

22. Yan, M.; Sha, A.; Zhang, W.; Wang, Y. Recovery and recrystallization behavior of large sized beta phase grains in TC18 Titanium alloy during annealing process. Mater. Sci. Forum 2015, 817, 263-267. [CrossRef]

23. Jackson, M.; Dashwood, L.; Flower, H.M. Application of novel technique to examine thermomechanical processing of near beta alloy Ti-10V-2Fe-3Al. Mater. Sci. Technol. 2000, 16, 1437-1444. [CrossRef]

24. Li, K.; Yang, P. The formation of strong $\{100\}$ texture by dynamic strain-induced boundary migration in hot compressed Ti-5Al-5Mo-5V-1Cr-1Fe alloy. Metals 2017, 7, 412. [CrossRef]

25. Cui, Y.M.; Zheng, W.W.; Zhang, F.; Sha, A.X. Effect of $\beta$ annealing and near $\beta$ zone hot deformation on the microstructure and texture of TC18 alloy. Mater. Sci. Forum 2016, 849, 226-231. [CrossRef]

26. Primig, S.; Leither, H.; Knabl, W.; Lorich, A.; Clemens, H.; Stickler, R. Texture evolution during dynamic recovery and static recrystallization of molybdenum. Metall. Mater. Trans. A 2012, 550, 19-30. 